\title{
Biodiesel Production from Crude Cottonseed Oil: An Optimization Process Using Response Surface Methodology
}

\author{
Xiaohu Fan ${ }^{*}, 1$ Xi Wang ${ }^{*}, 2$ and Feng Chen ${ }^{1}$ \\ ${ }^{1}$ Department of Food Science and Human Nutrition, Clemson University, Clemson, SC 29634, USA \\ ${ }^{2}$ Department of Genetics and Biochemistry, Clemson University, Clemson, SC 29634, USA
}

\begin{abstract}
Biodiesel, known as fatty acid methyl ester (FAME), was produced from crude cottonseed oil (triglycerides) by transesterification with methanol in the presence of sodium hydroxide. This process was optimized by applying factorial design and response surface methodology (RSM) with SAS and PSIPLOT programs. A second-order mathematical model was obtained to predict the yield as a function of methanol/oil molar ratio, catalyst concentration, reaction temperature, and rate of mixing. Based on ridge max analysis and RSM, as well as economic cost consideration, the practical optimal condition for the production of biodiesel was found to be: methanol/oil molar ratio, 7.9 ; temperature, $53{ }^{\circ} \mathrm{C}$; time, $45 \mathrm{~min}$; catalyst concentration, $1.0 \%$; and rate of mixing, $268 \mathrm{rpm}$. The optimized condition was validated with the actual biodiesel yield of $97 \%$. Furthermore, the biodiesel was confirmed by HPLC analyses that triglycerides of cottonseed oil were almost completely converted to FAME.
\end{abstract}

Keywords: Biodiesel, crude cottonseed oil, response surface methodology (RSM), transesterification.

\section{INTRODUCTION}

Biodiesel, the most promising alternative diesel fuel, has received considerable attention in recent years due to its following merits: biodegradable, renewable, non-toxic, less emission of gaseous and particulate pollutants with higher cetane number than normal diesel. In addition, it meets the currently increasing demands of world energy that, in a large degree, is dependent on petroleum based fuel resources, which will be depleted in the foreseeable future if the present pattern of energy consumption continues.

Biodiesel is derived from vegetable oils or animal fats through transesterification [1]. Transesterification is also called alcoholysis, which uses alcohols in the presence of catalyst (e.g., base, acid or enzyme depending on the free fatty acid content of the raw material) that chemically breaks the molecules of triglycerides into alkyl esters as biodiesel fuels and glycerol as a by-product. The commonly used alcohols for the transesterification include methanol, ethanol, propanol, butanol, and amyl alcohol. Methanol and ethanol are adopted most frequently, particularly the former due to its low cost.

Commonly used feedstocks (vegetable oil) for transesterification include soybean oil, rapeseed oil, etc. In recent years, there exist active researches on biodiesel production from cottonseed oil [2-7], of which the conversion between $72 \%$ and $94 \%$ was obtained by enzyme catalyzed transesterification when the refined cottonseed oil reacted with short-chain primary and secondary alcohols. The application of solid acid catalysts on cottonseed oil transesterification was investigated by $\mathrm{He}$ et al. The results

*Address correspondence to these authors at the Clemson University, Clemson, SC 29634, USA; Tel: + 864-656-1291; Fax: + 864-656-0331;

E-mails: xfan@biofuels.coop, xiwclemson@gmail.com showed that the yield of methyl ester was above $90 \%$ after 8 hours of reaction [8]. In contrast, transesterifying cottonseed oil by microwave irradiation could produce a biodiesel yield in the range of $89.5-92.7 \%$ [9]. No matter what kind of catalysts or approaches were applied, all those studies aimed to produce high yield of biodiesel by optimized reaction conditions based on optimized parameters in terms of alcohol/oil molar ratio, catalyst concentration, reaction temperature, and time. However, nearly in all studied cases, there existed complex interactions among the variables that remarkably affected the biodiesel yield. Moreover, it seems unrealistic to optimize the process by the traditional 1-factorat-a-time approach, which is time-consuming and nearly impossible to achieve the true optimal condition. Alternatively, response surface methodology (RSM), an experimental strategy described first by Box and Wilson for seeking an optimal condition for a multivariable system, is an efficient technique for processing optimization [10]. In this study, RSM was applied to optimize the transesterification of crude cottonseed oil with methanol in the presence of sodium hydroxide to produce biodiesel with the highest yield.

\section{MATERIALS AND METHODOLOGY}

\subsection{Materials}

Methanol and sodium hydroxide were purchased from Fisher Scientific (Suwanee, GA, USA). Crude cottonseed oil derived from expeller, i.e. screw pressed cottonseed, was obtained from the Elgin Cotton Oil Mill, Inc. (Elgin, TX, USA). The Gyrotory water bath shaker was purchased from New Brunswick Scientific Co. Inc. (NJ, USA).

\subsection{Characterization of Crude Cottonseed Oil}

An aliquot of about $10 \mathrm{mg}$ of oil was weighed and mixed with $2 \mathrm{ml}$ of hexane, then $0.2 \mathrm{ml}$ of $2 \mathrm{M}$ methanolic $\mathrm{KOH}$ was added for transesterification. The mixture was vortexed 


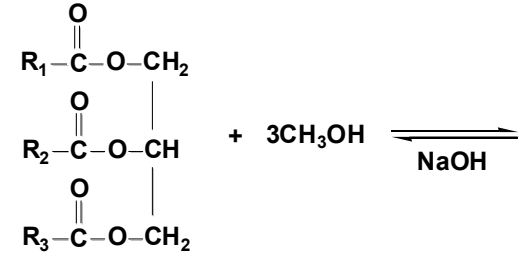

COTTONSEED OIL METHANOL
Fig. (1). Chemical reaction for biodiesel production.

for $2 \mathrm{~min}$ at room temperature, and centrifuged, then an aliquot ( 2 microliters) of the hexane layer was collected for GC analysis. Shimadzu's GC-FID system, used for the qualitative and quantitative analyses of fatty acids of the crude cottonseed oil and biodiesel consists of a GC-17A, a flame ionization detector, and a DB-WAX capillary column $(60 \mathrm{~m} \times 0.25 \mathrm{~mm}$, thickness $=0.25 \mu \mathrm{m} ; \mathrm{J} \& \mathrm{~W}$ Scientific $)$. The initial temperature for oven was set at $180{ }^{\circ} \mathrm{C}$ and held for 2 $\min$. Then the temperature increased from $180{ }^{\circ} \mathrm{C}$ to $250{ }^{\circ} \mathrm{C}$ at the ramp of $5^{\circ} \mathrm{C} / \mathrm{min}$ and held at $250{ }^{\circ} \mathrm{C}$ for $30 \mathrm{~min}$. The injector and detector were maintained at $200{ }^{\circ} \mathrm{C}$ and $220^{\circ} \mathrm{C}$, respectively. Helium was used as a carrier gas, and its flow rate was kept at $1.5 \mathrm{ml} / \mathrm{min}$. Free fatty acid content of the cottonseed oil was measured according to the A.O.C.S. Official Method Ca 5a-40 [11].

\subsection{Transesterification of Crude Cottonseed Oil}

The crude cottonseed oil reacted with methanol in the presence of sodium hydroxide to produce methyl esters of fatty acids (biodiesel) and glycerol (Fig. 1). To optimize the above transesterification process, a three-level-five-factor $\left(2^{5}\right)$ fractional factorial experimental design was employed (Table 1). The crude cottonseed oil was precisely quantitatively transferred into an Erlenmeyer flask immersed in the Gyrotory water bath shaker. Then specific amount of sodium hydroxide (by weight of crude cottonseed oil) dissolved in the required amount of methanol was added. The reaction flask was kept in the water bath under constant temperature with defined agitation throughout the reaction. At the defined time, sample was taken out, cooled, and the biodiesel (i.e. the methyl ester in the upper layer) was separated from the by-product (i.e., the glycerol in the lower layer) by settlement overnight under ambient condition. The percentage of the biodiesel yield was determined by comparing the weight of up layer biodiesel with the weight of crude cottonseed oil added.

\subsection{Purification of Methyl Ester Phase}

Since the remaining unreacted methanol in the biodiesel has safety risks and can corrode engine components, the residual catalyst (sodium hydroxide) can damage engine

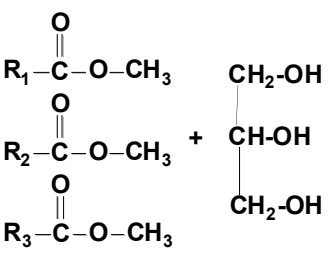

BIODIESEL GLYCEROL components, and soap in the biodiesel can reduce fuel lubricity and cause injector coking and other deposits [12], the methyl ester layer (biodiesel) was washed by mist washing with $1: 1$ volume of hot distilled water (about $60^{\circ} \mathrm{C}$ ) using a misting nozzle to make a fine, gentle mist, which was allowed to float over the surface of the biodiesel. After removing the unreacted methanol, the remaining catalyst, and soap, the washed biodiesel was placed into an oven at 55 ${ }^{\circ} \mathrm{C}$ to evaporate the water residue and then dried with sodium sulphate so as to minimize the undesired biological growth.

\subsection{HPLC Methods}

Reverse phase HPLC was used to qualitatively and quantitatively analyze the conversion of triglyceride into biodiesel. The Shimadzu HPLC system consisted of an evaporative light scattering detector (ELSD) with a Phenomenex Gemini C18 column $(250 \times 4.6 \mathrm{~mm}, 5 \mu \mathrm{m})$. HPLC grade acetonitrile (A) and dichloromethane (B) were selected as the mobile phase. The gradient program was as follows: Time: $(0,5,30,32,35 \mathrm{~min})$ for solvent $\mathrm{B}$ : $(0,15$, $70,70,0 \%)$. The flow rate of the mobile phase was 1.0 $\mathrm{ml} / \mathrm{min}$. Twenty microliters of the diluted biodiesel sample was injected via autosampler.

\section{RESULTS AND DISCUSSION}

Usually crude cottonseed oil contains palmitic acid (22$26 \%$ ), oleic acid (15-20\%), linoleic acid (49-58\%) and approximately $10 \%$ mixture of arachidic acid, behenic acid and lignoceric acid, as well as about $1 \%$ sterculic and malvalic acids [13]. In this study, the used crude cottonseed oil contained $23.67 \%$ of palmitic acid, $17.09 \%$ of oleic acid, and $50.33 \%$ of linoleic acid.

Since higher amount of free fatty acids (FFA) $(>1 \% \mathrm{w} / \mathrm{w})$ in the feedstock can directly react with the alkaline catalyst to form soaps, which are subject to form stable emulsions and thus prevent separation of the biodiesel from the glycerol fraction and decrease the yield [14], it is better to select reactant oils with low FFA content or to remove FFA from the oil to an acceptable level before the reaction. Nevertheless, the FFA (calculated as oleic acid) content of the crude cottonseed oil used in this experiment was only

Table 1. 3-level-5-factor Experimental Design

\begin{tabular}{|c|c|c|c|c|c|}
\hline Level & $\begin{array}{c}\text { Methanol/oil molar } \\
\text { ratio }\end{array}$ & $\begin{array}{c}\text { Catalyst/oil } \\
\mathbf{( w t )}\end{array}$ & $\begin{array}{c}\text { Temperature } \\
\left(\mathbf{(}^{\circ} \mathbf{C}\right)\end{array}$ & $\begin{array}{c}\text { Time } \\
(\mathbf{m i n})\end{array}$ & 30 \\
\hline \hline 1 & 4 & 0.5 & 45 & 55 & 250 \\
\hline 2 & 6 & 1 & 65 & 300 \\
\hline 3 & 8 & 1.5 & 60 & 350 \\
\hline
\end{tabular}


Table 2. Experimental Matrix for the Factorial Design and Center Points

\begin{tabular}{|c|c|c|c|c|c|c|c|c|c|c|c|}
\hline \multirow{2}{*}{ Run } & \multicolumn{5}{|c|}{ Original Factors and Levels } & \multicolumn{5}{|c|}{ Coded Factors and Levels } & \multirow{2}{*}{$\begin{array}{l}\text { Yield } \\
\text { Y (\%) }\end{array}$} \\
\hline & $\mathbf{A}$ & B & $\mathbf{C}$ & $\mathbf{D}$ & $\mathbf{E}$ & $\mathbf{X}_{1}$ & $\mathbf{X}_{2}$ & $\mathbf{X}_{3}$ & $\mathbf{X}_{4}$ & $\mathbf{X}_{5}$ & \\
\hline 1 & $4 / 1$ & 0.5 & 45 & 30 & 250 & -1 & -1 & -1 & -1 & -1 & 92.97 \\
\hline 2 & $8 / 1$ & 0.5 & 45 & 30 & 250 & +1 & -1 & -1 & -1 & -1 & 95.52 \\
\hline 3 & $4 / 1$ & 1.5 & 45 & 30 & 250 & -1 & +1 & -1 & -1 & -1 & 43.45 \\
\hline 4 & $8 / 1$ & 1.5 & 45 & 30 & 250 & +1 & +1 & -1 & -1 & -1 & 83.52 \\
\hline 5 & $4 / 1$ & 0.5 & 65 & 30 & 250 & -1 & -1 & +1 & -1 & -1 & 94.55 \\
\hline 6 & $8 / 1$ & 0.5 & 65 & 30 & 250 & +1 & -1 & +1 & -1 & -1 & 94.99 \\
\hline 7 & $4 / 1$ & 1.5 & 65 & 30 & 250 & -1 & +1 & +1 & -1 & -1 & 60.33 \\
\hline 8 & $8 / 1$ & 1.5 & 65 & 30 & 250 & +1 & +1 & +1 & -1 & -1 & 89.30 \\
\hline 9 & $4 / 1$ & 0.5 & 45 & 60 & 250 & -1 & -1 & -1 & +1 & -1 & 96.83 \\
\hline 10 & $8 / 1$ & 0.5 & 45 & 60 & 250 & +1 & -1 & -1 & +1 & -1 & 87.85 \\
\hline 11 & $4 / 1$ & 1.5 & 45 & 60 & 250 & -1 & +1 & -1 & +1 & -1 & 39.30 \\
\hline 12 & $8 / 1$ & 1.5 & 45 & 60 & 250 & +1 & +1 & -1 & +1 & -1 & 80.87 \\
\hline 13 & $4 / 1$ & 0.5 & 65 & 60 & 250 & -1 & -1 & +1 & +1 & -1 & 94.81 \\
\hline 14 & $8 / 1$ & 0.5 & 65 & 60 & 250 & +1 & -1 & +1 & +1 & -1 & 97.26 \\
\hline 15 & $4 / 1$ & 1.5 & 65 & 60 & 250 & -1 & +1 & +1 & +1 & -1 & 52.48 \\
\hline 16 & $8 / 1$ & 1.5 & 65 & 60 & 250 & +1 & +1 & +1 & +1 & -1 & 70.39 \\
\hline 17 & $4 / 1$ & 0.5 & 45 & 30 & 350 & -1 & -1 & -1 & -1 & +1 & 93.52 \\
\hline 18 & $8 / 1$ & 0.5 & 45 & 30 & 350 & +1 & -1 & -1 & -1 & +1 & 63.85 \\
\hline 19 & $4 / 1$ & 1.5 & 45 & 30 & 350 & -1 & +1 & -1 & -1 & +1 & 22.58 \\
\hline 20 & $8 / 1$ & 1.5 & 45 & 30 & 350 & +1 & +1 & -1 & -1 & +1 & 80.76 \\
\hline 21 & $4 / 1$ & 0.5 & 65 & 30 & 350 & -1 & -1 & +1 & -1 & +1 & 90.93 \\
\hline 22 & $8 / 1$ & 0.5 & 65 & 30 & 350 & +1 & -1 & +1 & -1 & +1 & 95.93 \\
\hline 23 & $4 / 1$ & 1.5 & 65 & 30 & 350 & -1 & +1 & +1 & -1 & +1 & 51.83 \\
\hline 24 & $8 / 1$ & 1.5 & 65 & 30 & 350 & +1 & +1 & +1 & -1 & +1 & 67.08 \\
\hline 25 & $4 / 1$ & 0.5 & 45 & 60 & 350 & -1 & -1 & -1 & +1 & +1 & 82.51 \\
\hline 26 & $8 / 1$ & 0.5 & 45 & 60 & 350 & +1 & -1 & -1 & +1 & +1 & 79.47 \\
\hline 27 & $4 / 1$ & 1.5 & 45 & 60 & 350 & -1 & +1 & -1 & +1 & +1 & 16.92 \\
\hline 28 & $8 / 1$ & 1.5 & 45 & 60 & 350 & +1 & +1 & -1 & +1 & +1 & 87.26 \\
\hline 29 & $4 / 1$ & 0.5 & 65 & 60 & 350 & -1 & -1 & +1 & +1 & +1 & 84.53 \\
\hline 30 & $8 / 1$ & 0.5 & 65 & 60 & 350 & +1 & -1 & +1 & +1 & +1 & 93.43 \\
\hline 31 & $4 / 1$ & 1.5 & 65 & 60 & 350 & -1 & +1 & +1 & +1 & +1 & 50.06 \\
\hline 32 & $8 / 1$ & 1.5 & 65 & 60 & 350 & +1 & +1 & +1 & +1 & +1 & 45.60 \\
\hline 33 & $6 / 1$ & 1.0 & 55 & 45 & 300 & 0 & 0 & 0 & 0 & 0 & 92.85 \\
\hline 34 & $6 / 1$ & 1.0 & 55 & 45 & 300 & 0 & 0 & 0 & 0 & 0 & 90.80 \\
\hline 35 & $6 / 1$ & 1.0 & 55 & 45 & 300 & 0 & 0 & 0 & 0 & 0 & 94.88 \\
\hline 36 & $6 / 1$ & 1.0 & 55 & 45 & 300 & 0 & 0 & 0 & 0 & 0 & 88.52 \\
\hline 37 & $6 / 1$ & 1.0 & 55 & 45 & 300 & 0 & 0 & 0 & 0 & 0 & 93.75 \\
\hline 38 & $6 / 1$ & 1.0 & 55 & 45 & 300 & 0 & 0 & 0 & 0 & 0 & 89.31 \\
\hline 39 & $6 / 1$ & 1.0 & 55 & 45 & 300 & 0 & 0 & 0 & 0 & 0 & 91.89 \\
\hline 40 & $6 / 1$ & 1.0 & 55 & 45 & 300 & 0 & 0 & 0 & 0 & 0 & 95.17 \\
\hline
\end{tabular}


$0.8 \%$, which was in an allowed level for being directly used for reaction with the alkaline catalyst to produce biodiesel.

The remaining main factors affecting the transesterification include reaction time, temperature, alcohol/oil molar ratio, rate of mixing, and catalyst concentration. In order to optimize the reaction condition to produce a high yield of biodiesel with high purity, response surface method was adopted to design the experiment. This methodology is a sequential process that usually starts at one reasonable operating condition, and then requires three stages to achieve a set of "better" conditions as rapidly and efficiently as possible. The first stage is to conduct several experiments to determine the direction so as to take the next move towards the optimal value. The second stage is to perform several runs along the direction as indicated by the first stage until an optimal value was approached. The last step is to deduce a mathematical model (equation) and profile the response surface to determine the optimal condition, which should be validated by the actual process.

\subsection{Fractional Factorial Design and First-Degree Polynomial Model Analysis}

Based on our experience and previous literature [15], the following factor (variable) levels were selected. The central point of the methanol/oil molar ratio was set at $6: 1$. The upper level of temperature was $65^{\circ} \mathrm{C}$, equal to the boiling point of methanol. Since high catalyst concentration can facilitate the soap formation, catalyst amount (catalyst/oil) of $1.5 \%$ (w) was chosen as the upper level of catalyst concentration. In addition, the central points for the reaction time and rate of mixing were $55 \mathrm{~min}$ and $350 \mathrm{rpm}$, respectively.

Table 2 shows the experimental matrix for the $2^{\mathrm{n}}$ factorial design, of which $\mathrm{n}$ was the number of factors. Herein, $\mathrm{n}$ equals to 5 that represented $\mathrm{A}, \mathrm{B}, \mathrm{C}, \mathrm{D}$ and $\mathrm{E}$, which corresponded to the uncoded values of the methanol/oil molar ratio, catalyst concentration $(\%)$, temperature $\left({ }^{\circ} \mathrm{C}\right)$, time (min), and rate of mixing (rpm), respectively. $X_{1}, X_{2}$, $\mathrm{X}_{3}, \mathrm{X}_{4}$ and $\mathrm{X}_{5}$ are coded values corresponding to the uncoded values of $\mathrm{A}$ to $\mathrm{E}$, respectively. The data in the last column of Table 2 indicates the response Y (\%) (yield of biodiesel) obtained from each experimental run. Eight additional center-point runs coded by 0 were performed to check the curvature in the response surface.

A complete statistical analysis of the first-degree polynomial model was performed using a single model in PROC REG of SAS program for Windows, Version 9.1, (Cary, NC, USA). The following expression for yield (Y) was obtained:

$\mathrm{Y}=77.95+7.67 \mathrm{X}_{1}-15.54 \mathrm{X}_{2}+2.70 \mathrm{X}_{3}-1.92 \mathrm{X}_{4}-5.26 \mathrm{X}_{5}$

(Eq. 1)

Table 3. SAS Results of Statistical Analysis for the $2^{5}$ Factorial Design

\begin{tabular}{|c|c|c|c|}
\hline Intercept & 77.95 & 196.25 & $<0.0001$ \\
\hline $\mathrm{X}_{2}$ & -15.54 & -34.99 & $<0.0001$ \\
\hline $\mathrm{X}_{3}$ & 2.70 & 6.07 & 0.0003 \\
\hline $\mathrm{X}_{5}$ & -5.26 & -11.83 & $<0.0001$ \\
\hline $\mathrm{X}_{1} * \mathrm{X}_{2}$ & 9.07 & 20.42 & $<0.0001$ \\
\hline $\mathrm{X}_{1} * \mathrm{X}_{3}$ & -3.02 & -6.80 & 0.0001 \\
\hline $\mathrm{X}_{2} * \mathrm{X}_{4}$ & -1.58 & -3.55 & 0.0075 \\
\hline $\mathrm{X}_{1} * \mathrm{X}_{3} * \mathrm{X}_{4}$ & -1.68 & -3.77 & 0.0054 \\
\hline $\mathrm{X}_{1} * \mathrm{X}_{3} * \mathrm{X}_{5}$ & -1.43 & -3.21 & 0.0123 \\
\hline $\mathrm{X}_{1} * \mathrm{X}_{4} * \mathrm{X}_{5}$ & 1.31 & 2.96 & 0.0181 \\
\hline $\mathrm{X}_{2} * \mathrm{X}_{3} * \mathrm{X}_{4}$ & -1.15 & -2.60 & 0.0318 \\
\hline $\mathrm{X}_{2} * \mathrm{X}_{3} * \mathrm{X}_{5}$ & -1.73 & -3.89 & 0.0046 \\
\hline $\mathrm{X}_{1} * \mathrm{X}_{2} * \mathrm{X}_{3} * \mathrm{X}_{4}$ & -1.10 & -2.48 & 0.0381 \\
\hline $\mathrm{X}_{1} * \mathrm{X}_{2} * \mathrm{X}_{3} * \mathrm{X}_{5}$ & -3.75 & -8.46 & $<0.0001$ \\
\hline $\mathrm{X}_{1} * \mathrm{X}_{2} * \mathrm{X}_{4} * \mathrm{X}_{5}$ & -1.19 & -2.68 & 0.0281 \\
\hline
\end{tabular}




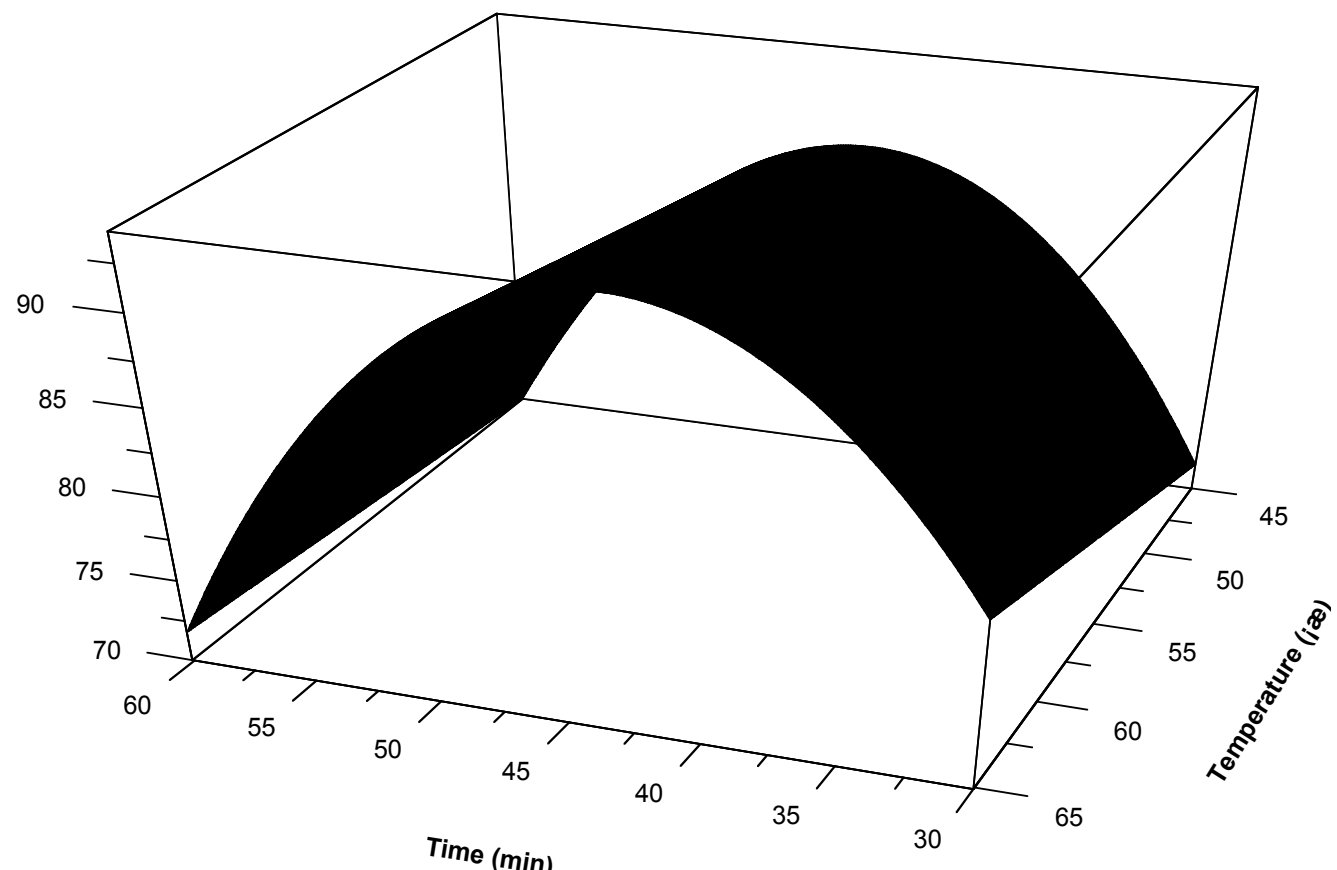

Fig. (2). Biodiesel yield vs. reaction temperature and time.

Yet, from the observed results shown in the Table $\mathbf{3}$, it is evident that there are interactions existing between the factors, and the response surface is more likely curved. Also, at $95 \%$ confidence level, all the factors, i.e., time, methanol/oil molar ratio, catalyst concentration, temperature, and rate of mixing, had significant influence on the reaction. Among them, methanol/oil molar ratio and temperature showed positive effects, while catalyst concentration, reaction time and rate of mixing had negative effects on the transesterification reaction. The negative effects of the catalyst concentration and rate of mixing (rpm) might be associated with the side reaction-soap formation, which was even more significant at higher levels of these variables.

The three-dimensional surface profiles (Fig. 2) plotted by the PSI-Plot (Poly Software International, Inc., Pearl River, NY, USA) showed that a higher yield could be obtained when the reaction time was kept at about $45 \mathrm{~min}$, so this factor was fixed at $45 \mathrm{~min}$. Other four factors, including methanol/oil molar ratio, catalyst concentration, temperature, and rate of mixing, fit into a second-order model to simplify the procedure. Thus, a new higher degree polynomial equation (Eq. 2) was used to express the processing:

$\mathrm{Y}=\beta_{0}+\sum_{i=1}^{4} \beta_{i} X_{i}+\sum_{i=1}^{4} \beta_{i i} X_{i}^{2}+\sum_{i=1}^{4} \sum_{j=1}^{i-1} \beta_{i j} X_{i} X_{j}$

\subsection{The Central Composite Design and the Second- Order Polynomial Model Analysis}

Eight additional experiments (Table 4) were carried out with a coded distance equaled to 2.0 when the reaction time was fixed at $45 \mathrm{~min}$. Then eight axial points were obtained. The matrix corresponding to the central composite design is shown in Table 4.

Using the RSREG program of SAS, a second-order polynomial equation (Eq. 3) for the experimental data was deduced as follows:

Table 4. Central Composite Design

\begin{tabular}{|c|c|c|c|c|c|c|c|c|c|}
\hline \multirow{2}{*}{ Run } & \multicolumn{4}{|c|}{ Original Factors and Levels } & \multicolumn{4}{|c|}{ Coded Factors and Levels } & \multirow{2}{*}{$\begin{array}{l}\text { Yield } \\
(\%)\end{array}$} \\
\hline & $\mathbf{A}$ & $\begin{array}{c}\text { B } \\
\text { (wt \%) }\end{array}$ & $\begin{array}{c}\mathrm{C} \\
\left({ }^{\circ} \mathrm{C}\right)\end{array}$ & D & $\mathbf{X}_{1}$ & $\mathbf{X}_{2}$ & $\mathbf{X}_{3}$ & $\mathbf{X}_{4}$ & \\
\hline 1 & 2 & 1 & 55 & 300 & -2 & 0 & 0 & 0 & 56.48 \\
\hline 2 & 10 & 1 & 55 & 300 & 2 & 0 & 0 & 0 & 87.61 \\
\hline 3 & 6 & 0 & 55 & 300 & 0 & -2 & 0 & 0 & 0 \\
\hline 4 & 6 & 2 & 55 & 300 & 0 & 2 & 0 & 0 & 10 \\
\hline 5 & 6 & 1 & 35 & 300 & 0 & 0 & -2 & 0 & 89.13 \\
\hline 6 & 6 & 1 & 75 & 300 & 0 & 0 & 2 & 0 & 82.04 \\
\hline 7 & 6 & 1 & 55 & 200 & 0 & 0 & 0 & -2 & 92.72 \\
\hline 8 & 6 & 1 & 55 & 400 & 0 & 0 & 0 & 2 & 89.36 \\
\hline
\end{tabular}

A: Methanol/oil molar ratio; B: Catalyst/oil (wt \%); C: Temperature $\left({ }^{\circ} \mathrm{C}\right)$; D: Rate of mixing 
$\mathrm{Y}=92.53+7.71 \mathrm{X}_{1}-10.36 \mathrm{X}_{2}+1.21 \mathrm{X}_{3}-3.79 \mathrm{X}_{4}-$

$3.08 \mathrm{X}_{1}^{2}+9.07 \mathrm{X}_{1} \mathrm{X}_{2}-21.09 \mathrm{X}_{2}^{2}-3.02 \mathrm{X}_{1} \mathrm{X}_{3}-0.67 \mathrm{X}_{2} \mathrm{X}_{3}+$

$0.30 \mathrm{X}_{3}{ }^{2}-0.14 \mathrm{X}_{1} \mathrm{X}_{4}-0.84 \mathrm{X}_{2} \mathrm{X}_{4}+0.59 \mathrm{X}_{3} \mathrm{X}_{4}+1.66 \mathrm{X}_{4}{ }^{2}$

The analysis of variance revealed that this model was adequate to express the actual relationship between the response and significant variables, with a satisfactory coefficient of determination $\left(R^{2}=0.84\right)$, which indicated $84 \%$ of the variability in the response could be explained by the 2 nd-order polynomial predictive equation given above. Also, the $P$-value of the lack of fit in 0.061 confirmed that the new polynomial model fit the processing.

\subsection{The Response Surface and Ridge Max Analysis}

The 3D response surface profile and its contour of the optimal production of biodiesel is shown in Fig. (3) based on Eq. 3, from which the variables of temperature and rate of mixing are fixed at central coded levels (i.e., temperature $=55$ ${ }^{\circ} \mathrm{C}$, rate of mixing $=300 \mathrm{rpm}$ ). The values in the picture have been transformed back to the uncoded (real) values. Fig. (3) clearly shows that the catalyst concentration around $1.0 \%$ (or within the range of $0.9 \sim 1.2 \%$ ) could most likely yield the maximal production of the biodiesel. The yield decreased when the catalyst concentration was beyond the above range. Since the methanol and triglyceride in the crude cottonseed oil are immiscible, addition of catalyst can facilitate the transesterification reaction, and rapidly increase the yield. However, when the catalyst concentration was too high, soap could be quickly formed which made the separation of glycerol from biodiesel more difficult, thus reduced the yield. In contrast, inadequate usage of catalyst could result in an incomplete reaction and a lower yield. The RSM shown in Fig. (3) exhibits the optimal value of the methanol/oil molar ratio for the yield, in which too high or too low values of the methanol/oil ratio have negative effects. This can be explained by the fact that the transesterification is an equilibrium reaction in which excessive amount of alcohol will, on one hand, drive the reaction to the right for more products; on the other hand, excess alcohol will help increase the solubility of glycerol resulting in the reaction driven to the left, thus decreasing the yield. Too low methanol/oil molar ratio also led to an incomplete reaction. Therefore, both catalyst concentration and methanol/oil molar ratio exhibited respective optimal values. The RSM demonstrated that the optimal conditions for catalyst concentration and methanol/oil molar ratio were about $1 \%$ and 7.5 , respectively, very close to the SAS ridge max analysis results that will be discussed in the following section.

The ridge max method, which computes the estimated ridge of optimum response when increasing radii from the center of the original design, was performed to attain an optimal condition for maximum biodiesel production. The ridge max analysis showed that the maximum yield could be theoretically approachable to $100 \%$ at $53{ }^{\circ} \mathrm{C}, \quad 7.9$ methanol/oil molar ratio, $1.0 \%$ catalyst concentration, and $268 \mathrm{rpm}$. Further biodiesel production using the above suggested optimal condition validated the yield in $97 \%$ that was very close to the theoretical value. Moreover, when we decreased the methanol/oil ratio to 6.0 while keeping all other parameters the same as those mentioned above, we found that the biodiesel yield could reach 95\%. Although the yield decreased from $97 \%$ to $95 \%$, from the cost-efficiency and processing safety point of view, we suggest using the molar ratio of methanol to oil at $6.0: 1$ for the biodiesel production. To ensure the conversion reaction, HPLC was used for product quality control. The results confirmed a nearly complete conversion based on the disappearance of triglyceride peaks (Fig. 4) and the appearance of FAME peaks (Fig. 5).

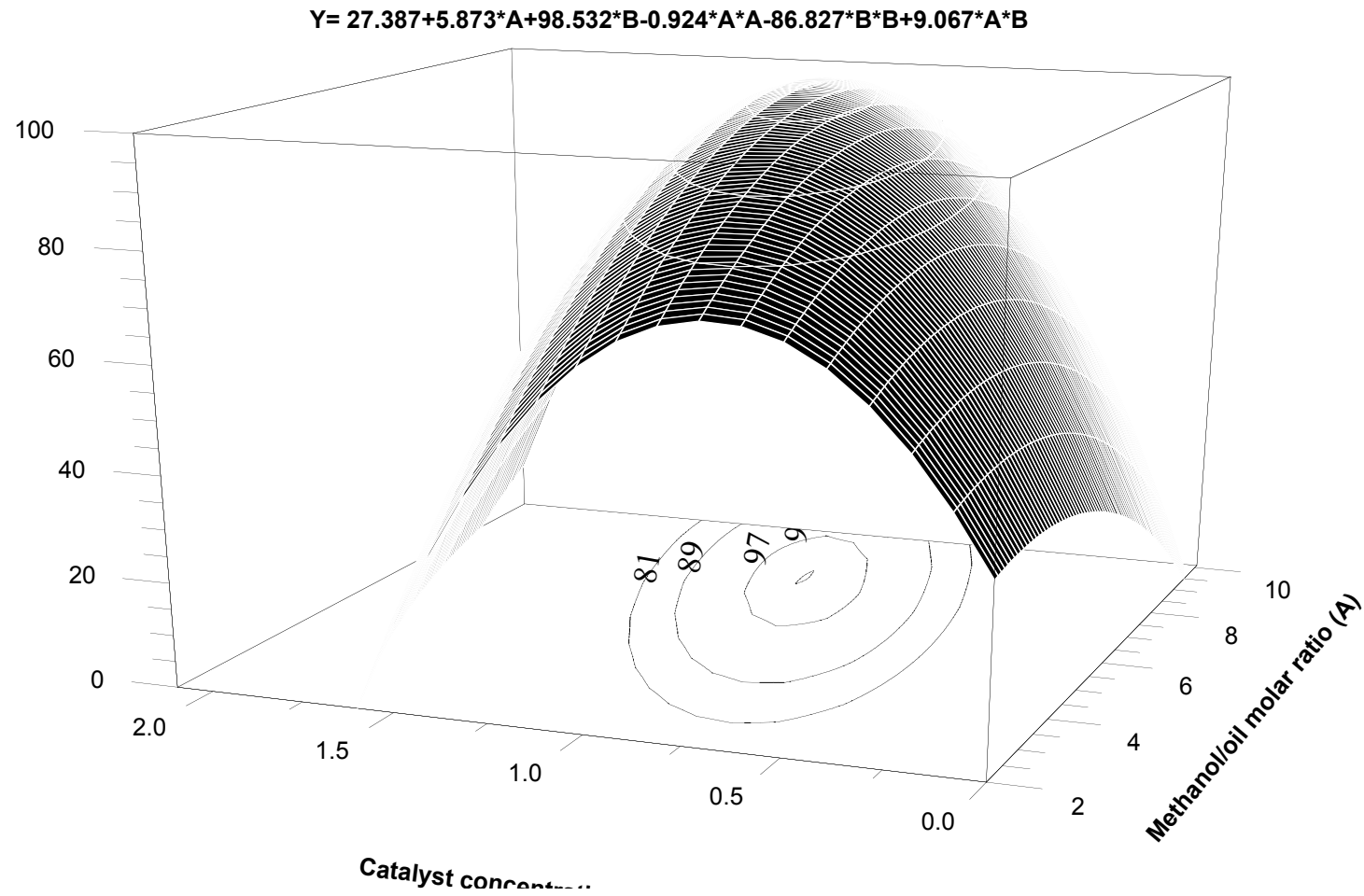

Fig. (3). Response surface and contour plot of the effects of methanol/oil molar ratio and catalyst on the yield of biodiesel. 


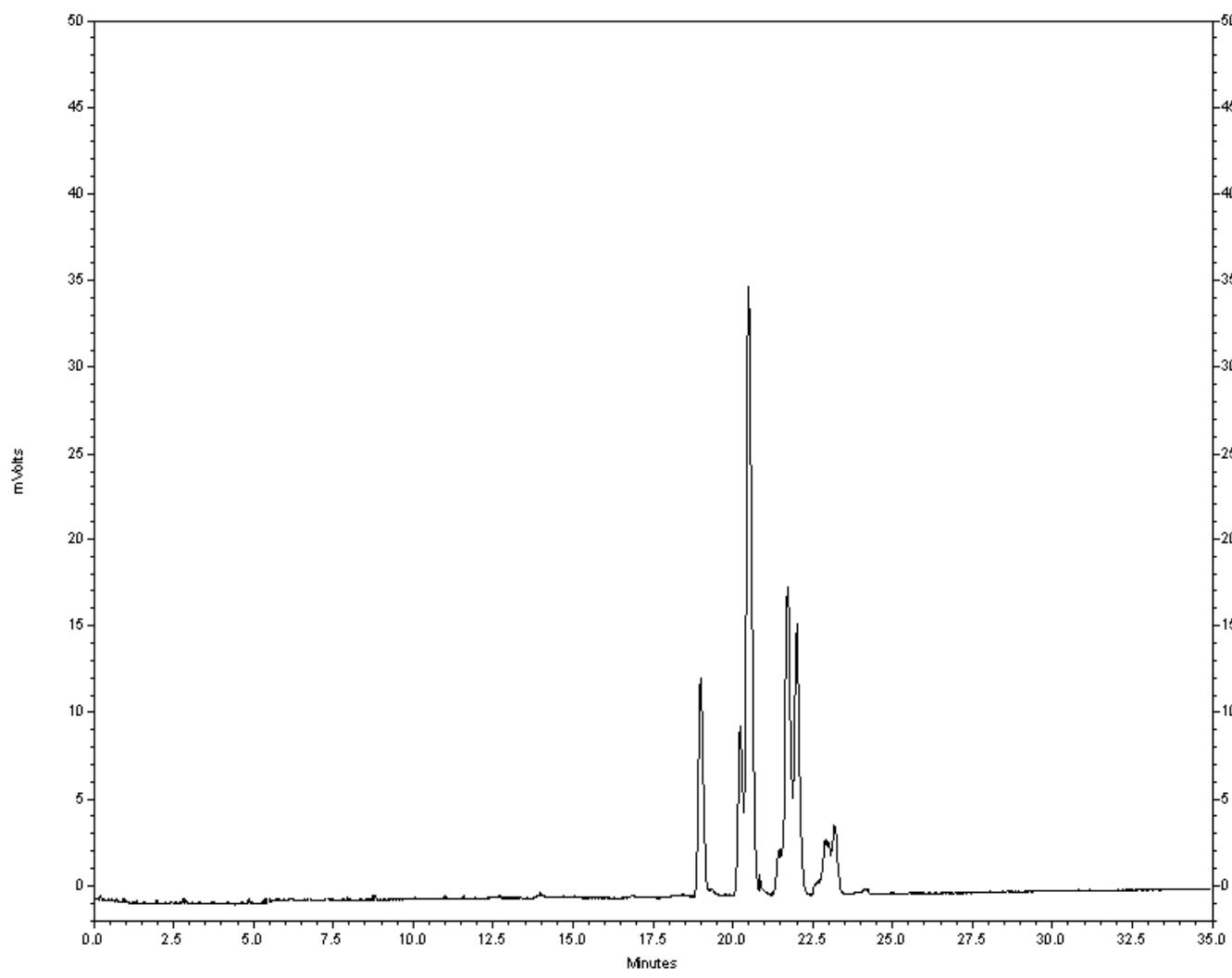

Fig. (4). HPLC chromatogram of crude cottonseed oil.

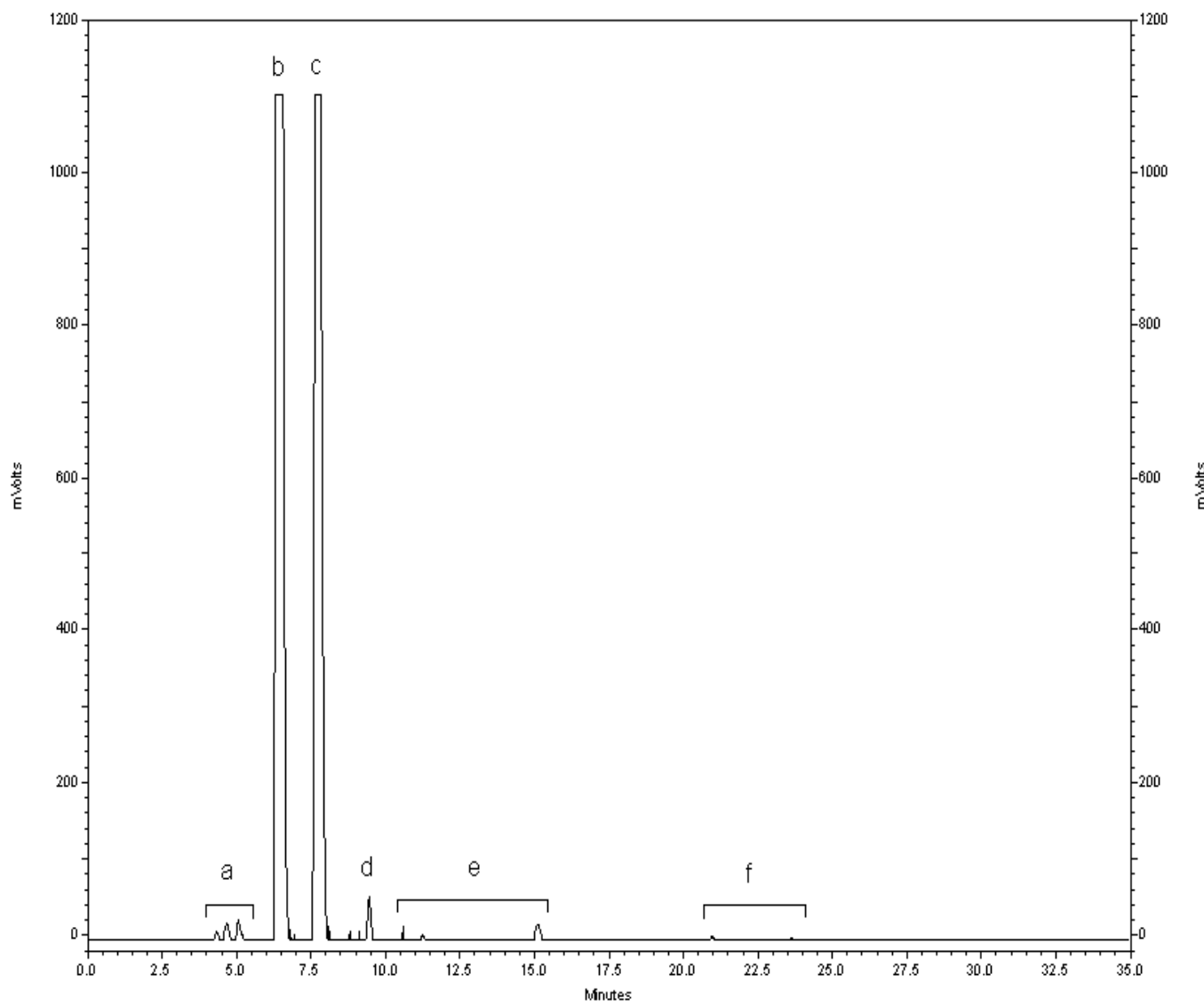

Fig. (5). HPLC chromatogram of biodiesel from crude cottonseed oil. (a) monoglycerides, (b) C18-2 (linoleic acid methyl ester), c C18-1 (oleic acid methyl ester), d C16-0 (palmitic acid methyl ester), e diglycerides, f unreacted triglycerides present in the biodiesel. 


\section{CONCLUSIONS}

In summary, RSM was successfully applied to assess the effects of multiple variables, including the alcohol/oil molar ratio, catalyst concentration, temperature, rate of mixing, and reaction time, for the production of biodiesel from the crude cottonseed oil. The experimental results suggested the optimal condition as the follows: methanol/oil molar ratio, 7.9; temperature, $53{ }^{\circ} \mathrm{C}$; time, $45 \mathrm{~min}$; catalyst concentration, $1.0 \%$; and rate of mixing, $268 \mathrm{rpm}$. This optimized condition was validated with the actual biodiesel yield in $97 \%$. Moreover, the decrease of the methanol/oil molar ratio from $7.9 / 1$ to $6.0 / 1$ while keeping other variable parameters in their respective optimal conditions could produce biodiesel with yield of $95 \%$. Since increasing the biodiesel yield by $2 \%$ with the cost of significantly increasing the molar ratio of methanol versus oil (6.0 to 7.9) does not appear to be costeffective, we suggest using the methanol/oil molar ratio at 6.0 for the optimal production of biodiesel from crude cottonseed oil.

\section{ACKNOWLEDGEMENTS}

The authors are very grateful to the Cotton Inc. and Clemson University Research Investment Initiative Program for their financial support. We also express our gratitude to Dr. Terry Walker and Mr. Hem Chandra Joshi for their analytical help on triglyceride analyses, and to Dr. Joe Toler for his help on statistical analysis.

\section{REFERENCES}

[1] Fukuda, H.; Kondo, A.; Noda, H. Biodiesel fuel production by transesterification of oils. J. Biosci Bioeng., 2001, 92, 405-416.

[2] Demirbas, A. Studies on cottonseed oil biodiesel prepared in noncatalytic SCF conditions. Bioresour. Technol., 2008, 99, 11251130.
[3] Cui, L.F.; Xiao, G.M.; Xu, B.; Teng, G.Y. Transesterification of cottonseed oil to biodiesel by using heterogeneous solid basic catalysts. Energy Fuel., 2007, 21, 3740-3743.

[4] Plentz, M.S.M.; Meneghetti, M.R.; Wolf, C.R.; Silva, E.C.; Lima G.E.S.; Coimbra, M.A.; Soletti, J.I.; Carvalho, S.H.V. Ethanolysis of castor and cottonseed oil: A systematic study using classical catalysts. J. Am. Oil Chem. Soc., 2006, 83, 819-822.

[5] Yücesu, H.S.; İlkiliç, C. Effect of cotton seed oil methyl ester on the performance and exhaust emission of a diesel engine. Energ Source Part A, 2006, 28, 389-398.

[6] Karabektas, M.; Ergen, G.; Hosoz, M. The effects of preheated cottonseed oil methyl ester on the performance and exhaust emissions of a diesel engine. Appl. Thermal Eng., 2008, 28, 21362143.

[7] Köse, Ö.; Tüter, M.; Aksoy, H.A. Immobilized candida antarctica lipase-catalyzed alcoholysis of cotton seed oil in a solvent-free medium. Bioresour. Technol., 2002, 83, 125-129.

[8] Chen, H.; Peng, B.X.; Wang, D.Z.; Wang, J.F. Biodiesel production by the transesterification of cottonseed oil by solid acid catalysts. Front. Chem. Eng. China, 2007, 1, 11-15.

[9] Azcan, N.; Danisman, A. Alkali catalyzed transesterification of cottonseed oil by microwave irradiation. Fuel., 2007, 86, 26392644.

[10] Kong, Q.; He, G.Q.; Chen, Q.H.; Chen, F. Optimization of medium composition for cultivating clostridium butyricum with response surface methodology. J. Food Sci., 2004, 69, M163-M168.

[11] AOCS official method Ca 5a-40. Free fatty acids. In: Sampling and analysis of commercial fats and oils, AOCS press, Champaign, 1997.

[12] Ryan, D.P.E. Biodiesel-a primer. Farm Energy Technical Note., 2004, 1-14.

[13] http://en.wikipedia.org/wiki/cottonseed_oil. Access on Feb. 10, 2010.

[14] Demirbaş, A. Biodiesel fuels from vegetable oils via catalytic and non-catalytic supercritical alcohol transesterifications and other methods: a Survey. Energy Convers. Manage., 2003, 44, 20932109.

[15] Fillières, R.; Benjelloun-Mlayah, B.; Delmas, M. Ethanolysis of rapeseed oil: quantitation of ethyl esters, mono-, di-, and triglycerides and glycerol by high performance size-exclusion chromatography. J. Am. Oil Chem. Soc., 1995, 72, 427-432. 